\title{
Is care of stillborn babies and their parents respectful? Results from an international online survey
}

\author{
Bethany Atkins ${ }^{1}$, Hannah Blencowe ${ }^{2}$, Fran Boyle ${ }^{3}$, Emma Sacks $^{4}$, Dell Horey ${ }^{5}$, and Vicki \\ Flenady $^{6}$ \\ ${ }^{1}$ University College London \\ ${ }^{2}$ Maternal, Adolescent, Reproductive \& Child Health (MARCH) Centre, London School of \\ Hygiene and Tropical Medicine, Keppel Street, London, WC1E 7HT \\ ${ }^{3}$ University of Queensland \\ ${ }^{4}$ John Hopkins School of Public Health \\ ${ }^{5}$ la Trobe University \\ ${ }^{6}$ Mater Research Institute, University of Queensland
}

October 27, 2021

\begin{abstract}
Objective To quantify parents' experiences of respectful care around stillbirth globally. Design Multi-country, online, crosssectional survey. Setting and Population Self-identified bereaved parents $(n=3769)$ of stillborn babies from 44 high- and middleincome countries. Methods Parents' perspectives of 7 aspects of care quality, factors associated with respectful care, and 7 bereavement care practices were compared across geographical regions using descriptive statistics. Respectful care was compared between country income groups using multivariable logistic regression. Main Outcome Measures Self-reported experience of care around the time of stillbirth Results A quarter (25.4\%) of 3769 respondents reported disrespectful care after stillbirth and $23.5 \%$ reported disrespectful care of their baby. Gestation $<30$ weeks, and primiparity were associated with disrespect. Reported respectful care was lower in middle-income countries (MICs) than in high-income countries ( $\mathrm{HICs})(\mathrm{aOR}=0.35,95 \% \mathrm{CI}$ (0.29-0.42), p <0.01). In many countries, aspects of care quality need improvement, such as ensuring families have enough time with providers. Participating respondents from Latin America and Southern Europe reported lower satisfaction across all aspects of care quality compared to Northern Europe. Unmet need for memory-making activities in MICs is high. Conclusions Despite improvements, many parents still experience disrespectful care around stillbirth. The gap between parents' access to memory-making activities in MICs and HICs needs urgent attention. Tweetable abstract A quarter of parents of stillborn babies experience disrespectful care. There is global unmet need for memory-making activities
\end{abstract}

\section{Hosted file}

ISA 2015 Stillbirth and respect quantitative v7.docx available at https://authorea.com/users/ 443153/articles/543212-is-care-of-stillborn-babies-and-their-parents-respectful-resultsfrom-an-international-online-survey

\section{Hosted file}

TABLES and FIGURES ISA 2015 respectful care v6.docx available at https://authorea.com/users/ 443153/articles/543212-is-care-of-stillborn-babies-and-their-parents-respectful-resultsfrom-an-international-online-survey 